\title{
THE PERFORMANCE OF ORGANIZATIONS IN THE CONTEXT OF THE VUCA WORLD
}

DOI: https://doi.org/10.18509/AGB.2021.12

UDC: 005.332.1:658.5(100)

\author{
Mihaela Minciu, Cristina Dima, Marius \\ Nicolae Pacurari, Andreea- Mariana Manta
}

The Bucharest University of Economic Studies, Romania

corresponding author:

\author{
submitted: 28.04 .2020 \\ accepted: 15.07 .2020 \\ published: 10.10 .2020
}

\begin{abstract}
Nowadays, more and more organizations are operating in a business world characterized by volatility, uncertainty, complexity and ambiguity - the VUCA world. The VUCA concept defines a society where rapid and frequent changes occur, with challenges at every step, often being difficult to predict future activities. In order for an organization to be able to operate in such an environment, it is necessary for them to update their strategy, taking into account equally both: the opportunities and the threats that may appear. Therefore, the aim of this paper is to analyze the main changes caused by an uncertain and unpredictable environment on the performance of organizations, starting from the present studies and researches from this area. In order to maintain their competitive advantage, companies must align their services and products to high quality standards so that they can satisfy all consumer needs. Regarding the employees of the organizations, they must acquire new skills and abilities, so that when a difficult situation is established, a situation that could lead to the failure of the organization's objectives, they should act as quickly as possible. For organizations to perform, taking into account the influences and constraints of the VUCA world, it is necessary for them to adapt to new changes in technology, using modern equipment and machinery, so that any problem that apparently does not have a solution to be resolved with minimal resource consumption.
\end{abstract}

Keywords: performance, VUCA world, tehnology.

\section{INTRODUCTION}

In the VUCA world, the business environment is characterized, most often by instability and uncertainty, due to the rapid changes of the market, the increasingly reduced level of resources required for the functioning of organizations and technological changes. Regardless of the area of activity, each organization establishes a strategy, respectively a set of objectives, both in the short and long term regarding the company's activities, a set of strategic options, respectively the main means of rational use of the company's resources (human, financial, material, informational) to achieve the objectives previously established in an effective and efficient way. Most organizations aim to achieve results that will keep them in the competitive environment and help them become more competitive: increasing market share, improving the organization's position on the market, developing skills and increasing the degree of cooperation between employees, increasing employee satisfaction with to the activity carried out [1]. Therefore, the concept of organizational performance refers to all the steps taken in an organization, in order to maximize the profit and obtain a superior competitive position. Practically, performance indicators represent the factors that best define the success or failure of the activity carried out in an organization [2]. In the VUCA business environment for organizations, the mission to be performing becomes increasingly difficult to achieve because they have to adapt their management system extremely quickly to the new standards and the projects carried out within the organizations have to be updated because the situation analyzed previous it has changed, and the information resulting from past research is no 
longer valid at the time of implementation. Measuring organizational performance can be achieved through two categories of methods: financial and non-financial. The financial methods are represented by the main economic indicators that characterize the activity of an organization (profit, turnover, internal rate of return, etc.), while non-financial methods refer to the objectives and expectations of the organization (level of consumer satisfaction, reputation, the brand, the quality of the products and services provided). Organizational performance also refers to the way in which a company operates on the market characteristic of a particular domain, having a much higher share than competitors [3]. While at the individual level, the characteristics of the VUCA environment refer to all the activities of the people carried out in a constantly changing world, at the organizational level they refer to the totality of the decision situations marked by uncertainty, as well as the reduced capacity of the companies to anticipate and manage the unexpected [4]. The performance of a company is closely linked to the interdependencies present in the environment in which it operates, as an organization can be considered an open system, being influenced by both the inputs to the company (information, production factors), the way they are processed and the integration of outputs (products and services) into the market. In the VUCA world, changes that affect the performance of organizations occur everywhere, some of them being easily identified and desired, while others occur in an unexpected way, with no cause. One of the most important factors that influence the performance level of the organization is innovation. Organizations need innovative approaches in terms of how goods are produced and to explain the multiple links that exist in how products are made and organizational performance [5]. Organizational innovation refers to taking over creative ideas and transforming them into new products and services or improving existing ones within the organization. The organizations are trying to adapt to the changes in the VUCA world as they hope that in this way

\section{LITERATURE REVIEW}

Organizational performance refers to how opportunities in the environment are capitalized, the degree of achievement of financial performance objectives and indicators, and how the they will prosper and can reach or exceed the level of performance previously established. Moreover, in the VUCA world, adapting to changes in the business environment is an essential condition for surviving for any organization, as more and more rapid changes are occurring in its components (at politic level, economic, legislative, technological) due to the intensification of competition and the development of telecommunications. The changes in the environment of the organization are also reflected on the performance indicators [6].

These are represented in particular by: technology development (most organizations need to adapt their equipment more and more quickly to the latest models in the field in order to remain or improve efficiency), fierce competitiveness in all areas (companies have difficulties in terms of regarding the procurement of resources and raw materials, these being more and more limited due to the high number of organizations of the same type), the interdependencies existing between the multiple components of the industry (all changes in the external environment determine the organizations to become more specialized, having employees which can easily handle hazard).

All the transformations in the business environment are of course reflected on the consumers as they change their perceptions and desires, so that the organizations must update their strategies to make products and provide high quality services. In principle, obtaining performance at the organizational level is closely linked to the competence of managers and executives, respectively their professional ability to solve certain problems characteristic of the occupied position and to take advantage of different opportunities. Thus the individual performances specific to the managers refer to: the quality of the decisions taken, the managerial instrumentation and the managerial methodologies used, the capacity to motivate the personnel, in the sense of determining them to obtain certain beneficial results for the organization, the vision and the degree of its adaptation to the change.

organizations manage to satisfy the interests of stakeholders (employees, shareholders, suppliers, local and regional authorities, customers, banking institutions etc.), in an unstable and uncertain 
business environment (VUCA environment). The conditions that define volatility refer to the major changes that take place within organizations, which are often difficult to predict and manage. If until recently the performance of the organizations was revealed only by means of the financial indicators realized, in the VUCA world this is no longer possible, as the data are often under the sign of uncertainty, the majority of the decisions being taken, especially depending on the vision, the leadership capacity and the emotions of the managers, in the absence of a reliable analysis that clearly presents the possible results that could be obtained. Moreover, if in the past the organizations were characterized by employees who have been in business for more than ten years, this aspect has changed, the performance indicators characteristic of human resources suffering fluctuations from day to day due to the employees who are always looking for new challenges and which almost every year change their job without first announcing the employer, but also because of the accelerated transition of an employee from a lower position to a higher position, often without a rigorous evaluation of the activity carried out by him.

The next characteristic of the VUCA world is the uncertainty, which is present today more than ever, as regards the reduced predictability of organizations to anticipate the positive or negative consequences of certain events due to missing data. In fact, although the purpose of an organization is clear, it is often difficult to achieve because the decisions characteristic of long-term objectives are difficult to accomplish, considering all the factors of influence, both internal and external (new technologies, frequent changes in consumer preferences, skills and competencies of employees, etc.) It is true the uncertainty within an organization directly affects its performance, because any decision taken under uncertain conditions, in the absence of accurate information can affect its entire production process, but the way in which managers establish and implement different innovative strategies can divide an uncertain future in a series of risk categories that can be managed and characterized from the point of view of the impact (financial, technological, logistical risks, risks related to human resources).

The complexity, the third characteristic of the VUCA world is quite obvious because today the business environment is complex in any area, having a lot of data, often incomplete and difficult to classify and interpret. The lack of clarity, the chain effects of a wrong decision, because in this complex environment there are a number of interdependencies between the departments of an organization affect the performance indicators. Thus managers from different hierarchical levels have to change their leadership style, so that representatives from each department can take part in the decision-making process so that the negative consequences that can appear on the level of all the systems in the organization, after choosing a decision variants to be identified and treated early.

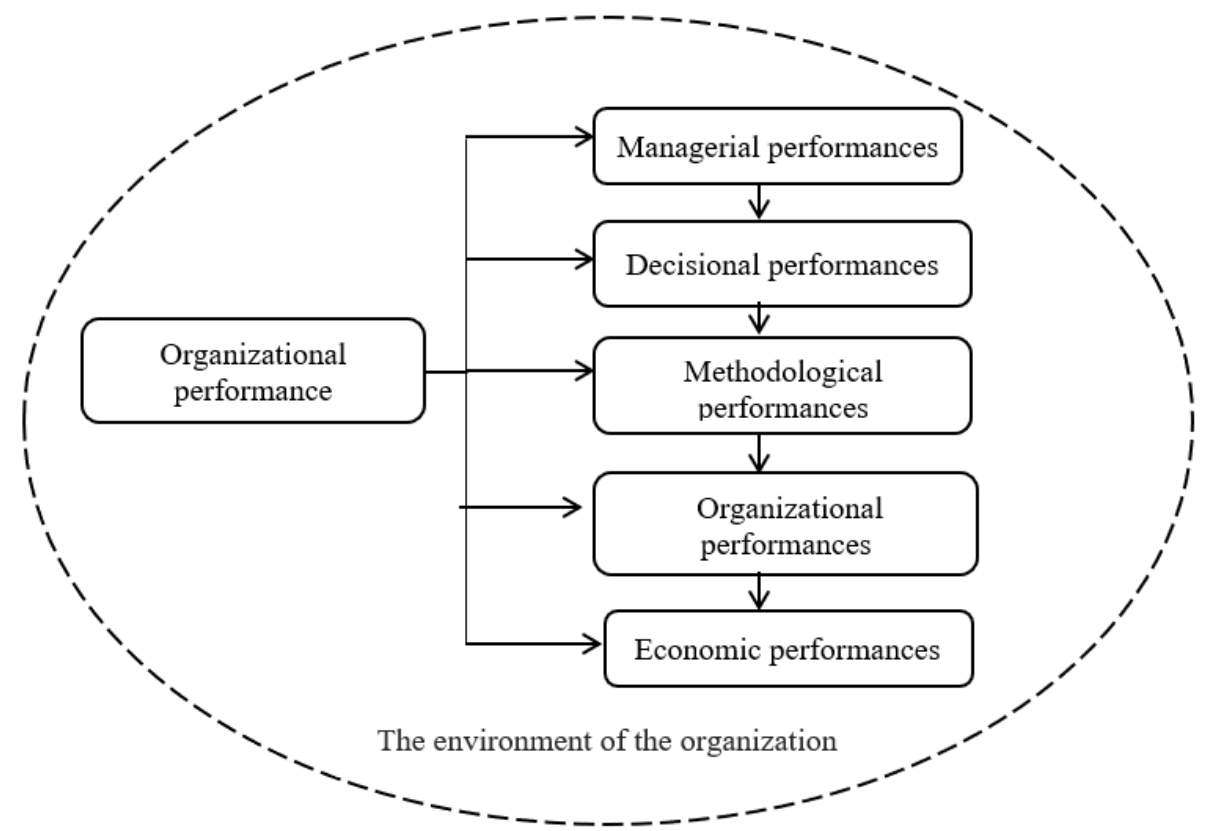

Figure 1. Organizational performance in the VUCA world. 
The last characteristic, the ambiguity refers to the multitude of decision-making options, which affect the basic values of the organization, as well as the way in which each employee performs within the organization [7]. If until recently the performance of an employee of the company could only be evaluated from the perspective of knowledge, in the VUCA world this is no longer possible, because the employees of the organizations have to broaden the level of their knowledge and skills, reacting quickly and effectively to changes from the environment. Therefore, the main forms of manifestation of organizational performance are represented by: managerial, decision-making, methodological, organizational, economic performance (figure 1). The managerial performances refer to the sphere of the managers of an organization because they are the ones who make sure that the management processes are carried out in good conditions, even in conditions of risk and uncertainty, respectively, they are the ones that foresee the objectives of the organization, organize and coordinate the activities and evaluates the results, both partial and final, to deal with all the negative consequences early on [8]. As most researchers in the field appreciate, the competitive advantage owned by a company at a given moment is directly influenced by the ability of managers to learn much faster than competitors, so that they can identify an opportunity much faster and they can cope with threats more easily [9].Decision performances refer to the totality of decisions taken within an organization related to the number of problems, because in an uncertain and volatile business environment a decision adopted in the past, regarding a particular project at the time of implementation, most often needs to be updated, in depending on the new environmental conditions. This category also refers to the ratio between the information provided to the employees, both at the

\section{METHODOLOGY}

The present paper was realized following the research and analysis of the specialized literature, on the way in which the organizational performance is influenced, taking into account all the conditions existing in a volatile and uncertain environment (VUCA environment). Thus, different articles and researches were studied that addressed aspects of the following areas: the main characteristics of the VUCA world and how they influence the business lower and higher hierarchical levels, compared to the required information. The methodological performances refer to all the systems and techniques used within an organization in carrying out the management processes and implicitly in the completion of each function (forecasting, organizing, coordinating, training and controlling evaluation). Managers in the VUCA world in order to be efficient and to manage more efficiently the possible risks that could have a negative impact on the organization, use a series of intelligent methods and softwares, such as: objective management, budget management, diagnosis, etc.Organizational performance highlights the way in which the work processes are carried out within the organization, emphasize the degree of accomplishment of the tasks by the employees, as well as the degree of accomplishment of the objectives, both fundamental and specific and individual. In a world in a continuous process of change for employees, it is becoming increasingly difficult to fulfill their tasks and goals within the planned time frame, because frequently arise urgent situations, so they must prioritize activities to solve problems that could prevent the production process from proceeding in good conditions.The economic performances aim to obtain much higher results than the competition and the situations registered in the years passed by an organization. These are reflected in terms of qualitative and quantitative indicators, respectively: number of employees, stocks of raw materials and products, company revenues, profit, labor productivity, etc. In the VUCA world, organizations in order to maintain or improve the value of economic performance indicators must have efficient managers, who have the necessary skills in managing work processes, so that any risk is identified and and treated early.

environment and implicitly the performance of organizations, the most important types of performance encountered within organizations, the factors that influence the performance of organizations, the effects of the VUCA world that causes organizations to adapt to changes in the environment in order to be performance.

In order to collect the data, different papers published in renowned specialized magazines in the 
economic field, have been analyzed: the articles that revealed how organizations must adapt to change and how this process should be carried out for organizations to become more efficient, even in the conditions of a complex and ambiguous environment. Also, special attention was paid to the national and international conferences where various aspects related to the VUCA world and organizational performance were discussed, as well as the media articles and reports published by different renowned companies.

Thus, if in the first part the theoretical notions will be used to present different aspects regarding the

\section{DISCUSSION AND RESULTS}

The performances of the organization are influenced, both directly and indirectly, by all the pressures of change in the internal and external environment, the companies having to acquire as many aspects as possible characteristic of this complex and volatile environment in order to survive further. In a volatile, uncertain, complex and ambiguous business environment (VUCA) change is present at all the hierarchical levels of an organization, and the way of answering and solving the problems that have arisen is a very important component of a performance management system. In order to study the way in which organizations maintain their level of performance, an important starting point is their resistance to the changes that take place in the external environment, as well as the initiatives of change [10].

The frequent changes existing in the field in which the organizations operate and in which they must adapt in order to maintain or increase their level of performance are determined by different causes, respectively: technological developments, access to information, decreasing the life cycle of products, the reprofessionalization of the employees and improving working conditions.

All of the changes that are occurring in the field of technology, which are becoming more and more frequent, require a number of changes among organizations, as employees have to broaden their knowledge, meaning that they must have a range of technical information, as well as a better understanding of the functioning of the different compartments of the organization (production, financial-accounting, human resources) to correlate their activity with them, so that when a crisis main components of the VUCA environment and their effects on the organizational performance, in the next part these aspects will be used to identify the most important factors which affects the performance of the organizations, as well as the main causes that determine the organizations to change the way that activities are carried out.

This paper represents a first step for organizations that frequently encounter problems, which apparently have no cause to be considered, managers and employees having to act quickly by making decisions without a scientific basis, so that the performance of the organization is not affected.

situation arises it will be quickly overcome. Easy access to information, knowledge explosion brings a series of changes among organizations because managers have to adapt very quickly to the changes that occurred when implementing a project within the company. Managers within organizations must have the skills and competencies needed to transform ideas into products and services, which will ensure the level of competitiveness of companies, although often in the VUCA world data is incomplete and frequently undergoes transformations.

Decreasing the life cycle of products is one of the most important causes leading to changes in the production process of organizations, since from month to month products appear more and more complex and cheaper, so that product created within an organization can be very easily overcome, especially in an uncertain environment.

The reprofessionalization of the employees refers to the increase of the intellectual work to the detriment of the physical one, because today the working conditions have changed in the majority of organizations being used different computer programs that warn the employees when the activities of a project carried out within the organization no longer lead to the realization of the objectives and to economic performance. Thus, all these changes characteristic of the VUCA world lead to the emergence of well-trained, motivated employees, capable of making decisions under uncertain and risky conditions.

The changes introduced within the organization can bring both improvements in the performance of the company, as well as deterioration, which is why it 
is very important to choose the moment when a certain change is introduced, before considering the possible effects [11]. All the necessary changes in the VUCA environment, which are realized within the organizations so that their performance is not affected, are influenced by the elements of the environment of economic, political, demographic, scientific, ecological (figure 2).

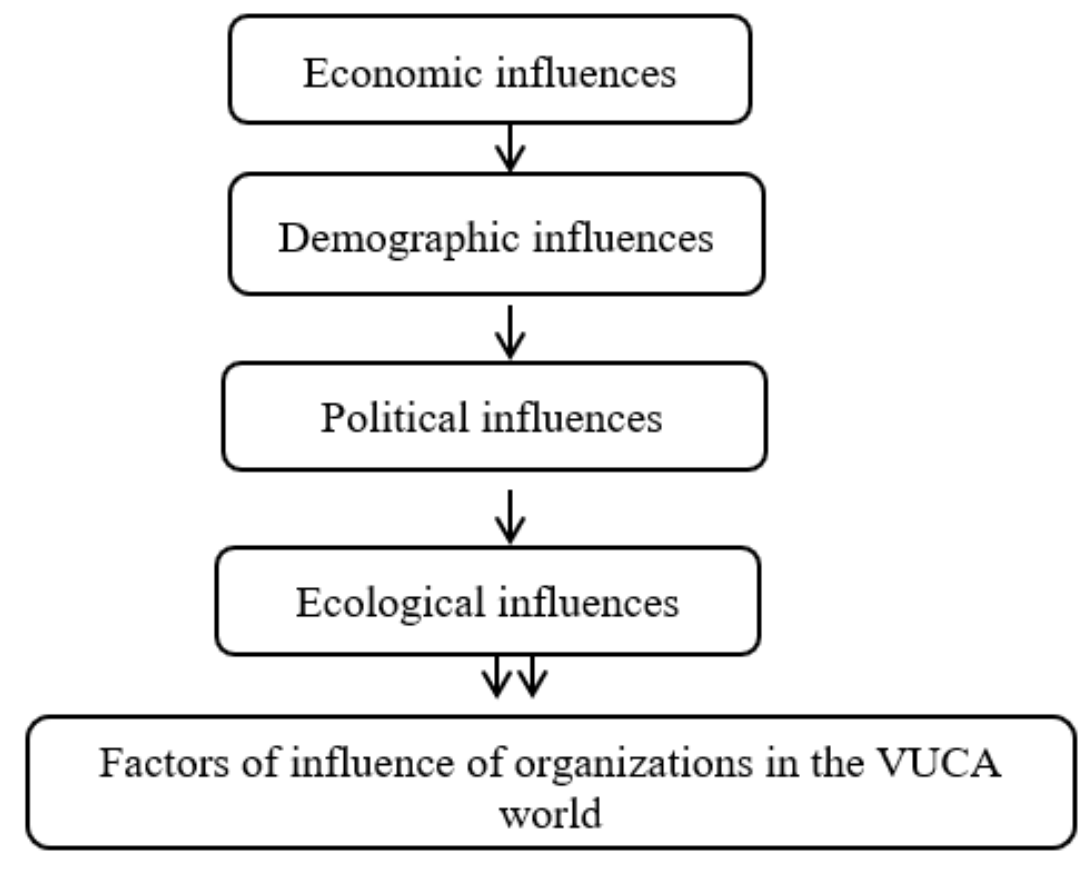

Figure 2. The influence of organizational performance in the VUCA world. Source: Authors'own contribution.

Economic influences refer to the main factors (market, banking system, investment regime, structure and level of demand, prices, competition etc.), depending on which different decisions are made regarding the need for supply, production and sale. In this uncertain environment, organizations more than ever have to adapt to market requirements, producing and offering consumers the desired products, thus satisfying the needs of society. The demographic influences affect the working population, because in the VUCA world, within the organizations, changes occur frequently in the structure of the employees, many of them resigning because they cannot adapt to the change. In this situation, the competence becomes central in organizing and carrying out all the activities specific to the personnel, as well as the essential condition that ensures the success of the organization in an increasingly changing competitive environment. The political influences

\section{CONCLUSIONS}

Adaptation to change is a vital condition for ensuring the success of organizations in the VUCA world, in particular because of the complexity of the competitive environment that can no longer be characterized only by the specific figures of the performance indicators of an organization (economic, commercial, financial profitability rate, profit, turnover etc.). Despite the fact that the are reflected on the organizations through the laws and regulations regarding the activity of a company (the way of setting up companies, the rules regarding the recording of expenses and incomes, the legislative regulations regarding the salary ceilings etc.).

Ecological influences refer to the natural resources, water and soil essential for any organization and population. In the current conditions of an uncertain world, in which there is a crisis of raw materials in almost any field, the management process plays a very important role, in order to create conditions that favor economic development. Therefore in the VUCA business environment, encouraging innovation and accepting change are the most important ways to ensure the performance of the organization, the employees being encouraged to issue new ideas, which they will implement after a preliminary analysis.

organizations are considered to be much more efficient when they carry out their activities and fulfill the objectives, according to the planning previously carried out, this thing in the business environment is no longer valid, the companies frequently having to adapt their management system, from the cause of certain changes. The changes occurring within an organization refer 
either to the emergence and implementation of a certain "novelty" that has the role of improving the production process, repairing mistakes made in the past or updating certain analyzes, researches done in the past, considering that when developing the actual activity of a project within organizations, the current state is frequently changed compared to the past time the project as conceived.

The main premises of the changes characteristic of the VUCA world include: the evaluation and control of the activity carried out, in order to anticipate future changes and to simulate some scenarios, in order to adopt the most appropriate decision, out of many possible alternatives, to identify the compartments within the organization that could suffer certain transformations, so that all those affected by a possible change of activity are involved, diminishing and eliminating the negative effects of the changes.

In order to remain competitive and to operate in the VUCA world in the future, each organization must identify early the main development modalities and ensure that the products and services offered accomplish the consumers' requirements and comply with market conditions. Innovation is one of the most important sources of ensuring an advantageous competitive position, as long as an organization has the necessary means and technologies to ensure the innovative effort.

\section{REFFERNCES}

[1] Ramezan, M., Sanjaghi, M. E. \& Baly, H. R. Organizational change capacity and organizational performance: An empirical analysis on an innovative industry. Journal of Knowledge-based Innovation in China, vol. 5 no. 3, pp 188212, 2013, doi: 10.1108/JKIC-07-2013-0012;

[2] Sethibe, T. \& Steyn, R. Innovation and organisational performance: A critical review of the instruments used to measure organisational performance. Southern African Journal of Entrepreneurship and Small Business Management vol. 8, no.1, pp 1-12, 2016;

[3] Ullah, A., Iqbal, S. \& Shams, R. Impact of CRM adoption on organizational performance Moderating role of technological turbulence. International Business Journal vol. 30, no. 1, pp 1059-5422, 2020, doi: 10.1108/CR-112019-0128

[4] Schmitt, L. nnovation Strategy is About Future Uncertainty: Creating an Innovation Strategy for a VUCA World. The ISPIM Innovation Forum, Boston, USA: The Inovo Group LLC, 2016, pp 1-7.

[5] Sardi, A. \& Sorano, E. Dynamic Performance Management: An Approach for Managing the Common Goods. Sustainability, vol.11, no. 6435, pp 1-22, 2019, doi:10.3390/su11226435;

[6] Krishnan, R. Organizational Change Readiness: Effects of Organizational Structure and Leadership Communication in Organizational Change (Doctoral dissertation, University of Maryland University College). United States of America: Published by ProQuest LLC, 2018;

[7] Rodriguez, A. \& Rodriguez, Y. Metaphors for today's leadership: VUCA world,millennial and "Cloud Leaders". Journal of Management Development, vol. 34, no. 7, pp 854-866, 2015;

[8] Verboncu, I., Apostu, C. M., D, G. D., \& Zalman, M. Management Eficienta, Eficacitate, Performante. Bucharest: Universitara, 2014;

[9] Bello, O. B. \& Adeoye, A.O. Organizational learning, organizational innovation and organizational performance: empirical evidence among selected manufacturing companies in Lagos metropolis, Nigeria, Journal of Economic and Mananagement, vol. 33, no. 3, pp 25-39, 2018, doi: 10.22367/JEM.2018.33.02;

[10] Naslund, D. \& Norrman, A. A performance measurement system for change initiatives. Business Process Management Journal, vol. 25, no.7, pp 1463-7154, 2019, doi: 10.1108/BPMJ-11-2017-0309;

[11] Popa, I. \& Popescu, D. (2012). Managing Organizational Change and Innovation Organizational Change Anticipattive Transforrmation vs. Abandonment of Change. QUALITY access to success, vol. 13, no. 127, pp 90-92, 201 